\title{
Uncertainty, Risk, and the Efficiencies of the Principal and the Agent: A Chance Constrained Data Envelopment Analysis Approach
}

\author{
Linlin Zhao $\mathbb{D}^{1}{ }^{1}$ Yong $\mathrm{Zha}^{2}$ and Liang Liang ${ }^{2}$ \\ ${ }^{1}$ School of Business, Nanjing Audit University, Yushan West Road 86, Nanjing, Jiangsu Province, 211815, China \\ ${ }^{2}$ School of Management, University of Science and Technology of China, 96 Jinzhai Road, Hefei, Anhui Province, 230026, China \\ Correspondence should be addressed to Linlin Zhao; lin87@mail.ustc.edu.cn
}

Received 17 July 2018; Revised 27 September 2018; Accepted 14 October 2018; Published 22 October 2018

Academic Editor: Vyacheslav Kalashnikov

Copyright (C) 2018 Linlin Zhao et al. This is an open access article distributed under the Creative Commons Attribution License, which permits unrestricted use, distribution, and reproduction in any medium, provided the original work is properly cited.

In a principal-agent relationship, although the principal (e.g., the investor) can control the inputs and decide the motivated payments to the agent (e.g., the top management team), she cannot have the ability to decide how many outputs she can be rewarded. Since the motivated payments the agent gains from the principal are closely related to the uncertain outputs, they also have the characteristic of uncertainty. Furthermore, the attitudes and behaviors of both parties, such as risk attitude of the principal/agent on the uncertainty of outputs/motivated payments, can have significant influence on the efficiencies of two parties and consequently affect the enthusiasm and effort of the agent. To address this issue, chance constrained data envelopment analysis (DEA) approach is proposed. Based on this stochastic approach, the measures of the principal's efficiency, the agent's efficiency, and the agent's effort level are provided. A case study of 16 China listed real estate companies validates our models and shows that the uncertainties of outputs and payments have significant influences on the efficiencies of the principal and the agent and the effort of the agent as well.

\section{Introduction}

The principal-agent relationships are ubiquitous in modern companies. The investors (the principal) delegate the top management teams (the agent) to control the firms with their professional knowledge and skills [1-3]. When these two parties engage in a business relationship, their interests are usually not perfectly aligned [4]. The principal's goal is to obtain more revenues while paying less compensation to the agent. Contrarily, the agent targets higher payments from the principal with lower human capitals (knowledge, ability) and fewer efforts. Usually, the agent's actions cannot be observed by the principal (hidden action) [5]. In such case, the principal faces the problem of providing incentives for the agent to take the desired actions and make the best of efforts [6].

In real application, although the principal can control the inputs and decide the motivated payments to the agent, she ("she" in this paper) cannot have the ability to decide how many outputs she can be rewarded. The reason lies in that the magnitude of the outputs depends upon various external factors such as the economic condition, demographic change, and other socioeconomic factors. Specifically, the agent's efforts can also have a significant influence on the quantities of the outputs. Such uncertain relationship is similar to the production relationships which are usually stochastic in nature. For example, complexity and uncertainty of manufacturing process enable the considerable variability of the product, and market unpredictability makes the new designs uncertain in new product development setting. Consequently, the principal's outputs, as well as the product and new designs in various scenarios, have to be considered as stochastic variables $[7,8]$. In addition, since the motivated payments the agent gains from the principal are closely related to the uncertain outputs, they also have the characteristic of uncertainty and are viewed as stochastic variables as well.

Intrinsically, the attitudes and behaviors of both parties, such as risk attitude of the principal/agent on the uncertainty of outputs/motivated payments and the extent 
of uncertainty of the outputs/motivated payments, can have significant influence on the efficiencies of two parties and consequently affect the enthusiasm and effort of the agent. Some researchers have discussed this issue. Holmstrom and Milgrom [9] predict a negative trade-off between risk and incentives. Prendergast [10] argues that an uncertain environment may lead to a positive risk-incentive relation. He et al. [11] study the interplay between profitability uncertainty and moral hazard and find that the relatively high risk aversion of the agent leads to the negative uncertainty-incentive relation, whereas the relatively low risk aversion leads to a positive uncertainty-incentive relation. However, little effort has been devoted to investigate the influence of uncertainty on the performance evaluations of the principal and the agent. Specifically, how to better describe the uncertain characteristics of the outputs and motivated payments? How to depict the risk attitudes of the principal and the agent on the uncertainty? How to identify the extent of uncertainty of the outputs and motivated payments? How does the effort of the agent affect the performances of both parties? How to depict the effort level in an explicit way?

This study is to answer the above questions. We first identify the factors with uncertain characteristic in the context of the principal and agent. The outputs of the principal and the payments the principal motivates the agent to are suggested to describe the uncertainties two parties have to deal with. We define various risk criterions to describe the risk attitudes of two parties. Derived from chance constrained programming (CCP) [12], we propose stochastic DEA models to investigate the efficiencies of two parties by incorporating the uncertain factors and the risk criterions of two parties. We further study how the effort level of the agent affects the efficiencies of both parties. By comparing with the efficiencies in cooperative and noncooperative situations, we can better characterize the relationship between the principal and the agent in uncertain environment.

The remainder of the paper is organized as follows. Section 2 introduces deterministic DEA models for the efficiencies of the principal and the agent and then proposes stochastic DEA models by considering the uncertainties of the outputs and motivated payments. Section 3 extends to the integrated models. Section 4 applies the proposed models to the efficiency evaluations of China listed real estate companies. Conclusions are provided in Section 5.

\section{Basic Models}

In classical principal-agent theory, the principal hires the agent for the services of the executives according to an explicit or implicit contract. The executives are granted certain decision-making powers to allocate the resources invested or owned by the principal and exert efforts to make profits for the principal. In addition, the principal has to pay an appropriate remuneration to the agent based on the quantity and quality of the services provided by the latter. Within the principal-agent relationship, the principal pursues an increase of her wealth, whereas the agent seeks higher wage subsidy and more luxury and leisure time. This inevitably leads to the conflicts of interest between them, which has

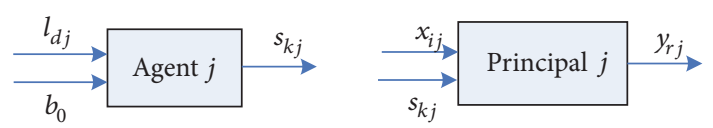

Figure 1: Principal-agent structure.

significant impacts on the performances of both parties. Next, we first propose the efficiency structures of the principal and the agent and analyze how to appropriately estimate the efficiencies from individual perspective of the principal and the agent. We then extend the situation in which the inputs and outputs are deterministic to a stochastic scenario where the uncertainties of inputs and outputs are taken into consideration.

Suppose there are $n$ independent decision maker units (DMUs), denoted by $D M U_{j}(j=1, \ldots, n)$. Figure 1 describes a typical principal-agent structure, in which each DMU is composed of two decision makers, the principal and the agent. In the principal's perspective, she invests various resources $x_{i j}(i=1, \ldots, I)$ to gain the outputs of the firm, $y_{r j}(r=1, \ldots, R)$. She also pays the executives with motivated payments, $s_{k j}(k=1, \ldots, K)$, which are viewed as one of the input classifications. In the agent's perspective, he ("he" in this paper) devotes human resources $l_{d j}(d=1, \ldots, D)$ and takes actions (efforts) $b_{0}$ to earn the payments $s_{k j}(k=1, \ldots, K)$ from the principal.

2.1. The Efficiency of the Principal. In this subsection, we first present a DEA model for measuring the efficiency of the principal in a deterministic perspective and then extend to a stochastic scenario by taking into consideration the uncertainties of the inputs (motivated payments) and outputs (organizational outcomes).

2.1.1. The Inputs and Outputs Are Deterministic. From the principal's perspective, her performance is influenced by the inputs (e.g., investment, motivated payments) and the organizational outcomes (e.g., profit, strategic change) and can be estimated by the deterministic DEA model (an outputoriented model with constant returns to scale) as follows:

$$
\begin{aligned}
e_{0}^{p}=\max & \sum_{r=1}^{R} U_{r} y_{r 0} \\
\text { s.t. } & \frac{\sum_{r=1}^{R} U_{r} y_{r j}}{\left(\sum_{k=1}^{K} \widetilde{W}_{k} s_{k j}+\sum_{i=1}^{I} V_{i}^{2} x_{i j}\right)} \leq 1, \\
& \sum_{k=1}^{K} \widetilde{W}_{k} s_{k 0}+\sum_{i=1}^{I} V_{i}^{2} x_{i 0}=1, \ldots, n \\
& U_{r}, \widetilde{W}_{k}, V_{i}^{2} \geq 0, \\
& r=1, \ldots, R, k=1, \ldots, K, i=1, \ldots, I
\end{aligned}
$$

where the symbols $U_{r}, \widetilde{W}_{k}$, and $V_{i}^{2}$ represent weight multipliers related to $r$ th output, $k$ th motivated payment, and $i$ th 
input, respectively. Suppose $U_{r}^{*}, \widetilde{W}_{k}^{*}$, and $V_{i}^{2 *}$ are the optimal multipliers of model (1) and the efficiency of the principal is defined as $e_{0}^{p}=\sum_{r=1}^{R} U_{r}^{*} y_{r 0}$.

2.1.2. The Outputs Are Stochastic. In classical principal-agent relationship, the principal has the incentive to induce higher efforts from the agent with higher payments, whereas the risk arises and the uncertainty of the outputs increases. There exists a challenge of how to estimate the efficiency of the principal when the outputs are uncertain and stochastic. Specifically, how is the performance of the principal affected by the risk attitude and criterion of the principal?

It is clear that model (1) can only deal with precise dataset when evaluating the efficiency of the principal but cannot effectively deal with the situation in which the organizational outcomes are uncertain and stochastic [13]. As Land et al. [7] argued, this uncertainty has significant influence on the efficiency evaluation results, and the concept of "efficiency" must somehow be related to how the DMUs deal with uncertainty. Otherwise, the efficiency results would be distorted and cannot comprehensively reflect the realities. Thus, model (1) cannot provide more accurate efficiency information for the principal in a setting with stochastic organizational outcomes. In what follows, a new stochastic DEA approach based on chance-constrained programming is developed to model the efficiency problem with the uncertainty of the organizational outcomes.

We first analyze the situation in which the principal can control the quantity of inputs $x_{i j}(i=1, \ldots, I)$ and motivated payments $s_{k j}(k=1, \ldots, K)$ as her decision variables, whilst being unable to control the outputs $y_{r j}(r=$ $1, \ldots, R)$, because these quantities depend upon external factors such as an economic condition, the agent's effort level, a demographic change, and other socioeconomic factors. Hence, the inputs and motivated payments are considered as deterministic variables and the outputs are considered as stochastic variables.

When the outputs $y_{r j}(r=1, \ldots, R)$ are considered as stochastic variables, DEA model for the efficiency of the principal can be formulated as

$$
\begin{aligned}
e_{0}^{p^{s}}=\max & E\left(\sum_{r=1}^{R} U_{r} \widehat{y}_{r 0}\right) \\
\text { s.t. } \quad & \operatorname{pro}\left(\frac{\sum_{r=1}^{R} U_{r} \widehat{y}_{r j}}{\left(\sum_{k=1}^{K} \widetilde{W}_{k} s_{k j}+\sum_{i=1}^{I} V_{i}^{2} x_{i j}\right)} \leq 1\right) \\
& \geq 1-\beta_{j}, \quad j=1, \ldots, n \\
& \sum_{k=1}^{K} \widetilde{W}_{k} s_{k 0}+\sum_{i=1}^{I} V_{i}^{2} x_{i 0}=1 \\
& U_{r}, \widetilde{W}_{k}, V_{i}^{2} \geq 0, \\
& r=1, \ldots, R, k=1, \ldots, K, i=1, \ldots, I
\end{aligned}
$$

In model (2), $\widehat{y}_{r j}$ is a stochastic variable representing the outputs of the principal are uncertain. The symbol pro denotes a "probability" measurement of the corresponding constraints and $\beta_{j}(j=1, \ldots, n)$ is a probability that the output/input ratio becomes more than 1 with a choice of weight multipliers. Thus, $\beta_{j}$ can be considered as a criterion representing to what extent the principal can bear the risk. On the other hand, $1-\beta_{j}$ indicates the probability of achieving the requirement. Thus, $1-\beta_{j}$ can be regarded as a confidence level. Note that the risk criterion $\beta_{j}$ is a prescribed value that is measured on the range between 0 and 1 . When $\beta_{j}=0$, it is required that the output/input ratio becomes no greater than unity; contrarily when $\beta_{j}=1$, model (2) omits the requirement under any selection of weight multipliers. It is stated that the confidence level can be set according to the requirement of managerial practice. In the related studies, $\beta_{j}$ s are commonly set as $0.05[7,14]$. Note also that " $E$ " indicates an expected value of the sum of weighted outputs $\widehat{y}_{r j}(j=1, \ldots, n)$. Suppose $U_{r}^{*}, \widetilde{W}_{k}^{*}$, and $V_{i}^{2 *}$ are the optimal solution of model (2) and the efficiency of the principal is defined as $e_{0}^{p s}=E\left(\sum_{r=1}^{R} U_{r}^{*} \hat{y}_{r 0}\right)$. Obviously, it is also stochastic since the principal cannot obtain deterministic organizational outcomes.

Model (2) is designed to handle the uncertain outputs. This model permits stochastic variation around the frontier, but the bulk of observations still fall on one side of it [7]. Obviously, the levels of outputs in model (2) need to be estimated in the process of efficiency evaluation. Note that model (2) is a complex nonlinear program, which needs a further reformulation to obtain its computational feasibility. See Appendix A (in the supplementary materials) for detailed transformation process.

2.1.3. The Motivated Payments Are Also Stochastic. In literature, given that the principal has the incentive to offer more payment to induce higher effort from the agent, the agent has to face higher risk. It in turn increases the compensation that the principal deserves to pay to the agent for bearing the risk [11]. That is, the motivated payments are also stochastic under the situation in which the principal intends to take risk of the organizational outcomes when contracting with the agent. In addition, since the motivated payments of the agent gains from the principal are closely related to the organizational outputs, it inevitably increases the stochasticity of the payments when the outputs are uncertain. In an effort to further investigate the impact of uncertainty of motivated payments on the performance of the principal, it is meaningful and practical to extend model (2) to consider the payments in a stochastic way.

Based on model (2), when the outputs $y_{r j}(r=1, \ldots, R)$ and motivated payments $s_{k j}(k=1, \ldots, K)$ are considered as stochastic variables, DEA model for the efficiency of the principal can be formulated as

$$
\begin{aligned}
e_{0}^{p^{s}}=\max & E\left(\sum_{r=1}^{R} U_{r} \widehat{y}_{r 0}\right) \\
\text { s.t. } & \operatorname{pro}\left(\frac{\sum_{r=1}^{R} U_{r} \widehat{y}_{r j}}{\left(\sum_{k=1}^{K} \widetilde{W}_{k} \widehat{s}_{k j}+\sum_{i=1}^{I} V_{i}^{2} x_{i j}\right)} \leq 1\right) \\
& \geq 1-\beta_{j}, \quad j=1,2, \ldots, n
\end{aligned}
$$




$$
\begin{aligned}
& E\left(\sum_{k=1}^{K} \widetilde{W}_{k} \widehat{s}_{k 0}\right)+\sum_{i=1}^{I} V_{i}^{2} x_{i 0}=1 \\
& U_{r}, \widetilde{W}_{k}, V_{i}^{2} \geq 0, \\
& \quad r=1, \ldots, R, k=1, \ldots, K, i=1, \ldots, I
\end{aligned}
$$

It is clear that the motivated payments $\widehat{s}_{k j}(k=1, \ldots, K)$ are considered as stochastic variables in model (3), contrary to the deterministic ones in model (2). In addition, the constraint $\sum_{k=1}^{K} \widetilde{W}_{k} s_{k 0}+\sum_{i=1}^{I} V_{i}^{2} x_{i 0}=1$ in model (2) is converted into $E\left(\sum_{k=1}^{K} \widetilde{W}_{k} \widehat{s}_{k 0}\right)+\sum_{i=1}^{I} V_{i}^{2} x_{i 0}=1$ in model (3). In this way, we can estimate the efficiency of the principal from a stochastic perspective and identify how the uncertainties of the outputs and payments affect the efficiency by comparing with the deterministic efficiency. Similar to model (2), model (3) can be transformed as a deterministic model. See Appendix A for detailed transformation process.

In real applications, the motivated payment is closely related to the organizational outcome. He et al. [11] define the payment as a linear function of fixed payment (i.e. fixed salary) and the output (i.e., profit). For example, $s=\alpha+\beta y$, where $\alpha$ is the fixed salary; $\beta$ is the incentive coefficient; $s$ is the payment; and $y$ is the organizational outcome. That is, $\widehat{s}$ can be replaced by $\widehat{s}=\alpha+\beta \widehat{y}$.

In practice, although the principal has the incentive to offer motivated payments to the executives based on their managerial performances and contributions to the organizational outcomes (e.g. profits), the inner principle which correlates $s$ with $\hat{y}$ does not perform actually. For example, although American International Group (AIG) loses \$100 billion in 2009, the group has resorted to U.S. government for $\$ 116.5$ billion for bonus of the executives. Another example is that the executives of BOE Technology Group Co., Ltd., receive a total payment of $¥ 10.49$ million whereas the net loss to parent company exceeds $¥ 2$ billion. In the book of "Pay without Performance," Bebchuk and Fried [15] demonstrate that the defects of corporate governance structure enable executives to use the power granted by the principal to affect their own pay. In operations, the executive pay is based on the bargaining power of executives and the board of directors. In addition, the "colleague friendship" and "team spirit" strengthen their psychological basis of mutual compromises. Moreover, since the directors preferring to executives have very little cost and the shareholders have limited rights of intervention, this makes the payment of executives isolated from the performance.

In addition, if the payment is considered to correlate with $\hat{y}$, the stochasticity of $\hat{y}$ increases the uncertainty of the payment, and the agent becomes more risky as well. Consequently, the efficiency of the agent is affected greatly. In this study, our objective is to propose models identifying whether the uncertainty of payment has influence on the efficiency in a simplified situation in which the uncertainty of payment is derived from its own variance. In this regard, model (3) can well satisfy this goal.
2.2. The Efficiency of the Agent. In previous subsection, we discuss the principal's performance in a selfish perspective. Since the principal and the agent are two independent decision makers in classical principal-agent problem and orient distinct objectives, it is valuable to further investigate the performance of the agent and identify how he exerts effort to facilitate the contract between two parties. We first present a DEA model to estimate the efficiency of the agent given that the payments are deterministic and then extend it to a stochastic model considering the uncertainty of the motivated payments.

2.2.1. The Payments Are Deterministic. Recall, in a conventional principal-agent relationship, the principal grants the managing and decision-making powers to the agent to accomplish her profit purpose. The agent also has the incentive to make good use of his human capital, such as professional knowledge and skills, and exerts appropriate effort to obtain motivated payment from the principal. In the agent's perspective, the inputs are human capital $l_{d j}(d=$ $1, \ldots, D)$ and the effort level $b_{0}$, and the outputs are motivated payments $s_{k j}(k=1, \ldots, K)$. Thus, the efficiency of the agent can be estimated by the DEA model which is similar to Banker et al. [16].

$$
\begin{aligned}
e_{0}^{a}=\max & \sum_{k=1}^{K} W_{k} s_{k 0} \\
\text { s.t. } & \frac{\sum_{k=1}^{K} W_{k} s_{k j}}{\left(\sum_{d=1}^{D} V_{d}^{1} l_{d j}+b_{0}\right)} \leq 1, \quad j=1, \ldots, n \\
& \sum_{d=1}^{D} V_{d}^{1} l_{d 0}+b_{0}=1 \\
& W_{k}, V_{d}^{1} \geq 0, \quad k=1, \ldots, K, d=1, \ldots, D \\
& b_{0} \text { is free }
\end{aligned}
$$

where $b_{0}$ is a variable input and indicates the effort level of the agent is variable. Based on the human capital $l_{d j}(d=$ $1, \ldots, D)$, the agent can adjust $b_{0}$ to correspond to the motivated payments $s_{k j}(k=1, \ldots, K)$. Given that $\widetilde{s}_{k j}(k=$ $1, \ldots, K)$ are the expectation of the agent, if $s_{k j}>\widetilde{s}_{k j}, b_{0}$ is suggested to be larger than 0 , which implies that the agent has the intention to take positive actions; if $s_{k j}<\widetilde{s}_{k j}, b_{0}$ is suggested to be lower than 0 , which means that he has the incentive to take negative actions. $s_{k j}=\widetilde{s}_{k j}$ is a special case in which the agent thinks that the payment is what he deserves and he will remain at current level of effort. In this situation, $b_{0}$ is equal to 0 . Thus, $b_{0}$ is a variable input and is assumed to freely change as the agent's willingness. Suppose $W_{k}^{*}$ and $V_{d}^{1^{*}}$ are the optimal multipliers of model (4) and the efficiency of the agent is defined as $e_{0}^{a}=\sum_{k=1}^{K} W_{k}^{*} s_{k 0}$.

2.2.2. The Payments Are Uncertain. In many settings, the motivated payments of the agent are not certain. For example, the principal adjusts the level of payment according to the performance of the agent in last periods and determines an 
appropriate payment in current period or links the payment with the organizational outcomes in a dynamic way. In addition, the principal may also adjust the payment for other special purposes. In this perspective, the motivated payment shows a relatively high uncertainty in real applications. In order to further investigate the impact of the uncertain motivated payments on the performance of the agent, it is meaningful and practical to extend model (4) to characterize the uncertainty of the payments. Based on model (4), we then propose the following model to evaluate the efficiency of the agent.

$$
\begin{aligned}
e_{0}^{a s}=\max & E\left(\sum_{k=1}^{K} W_{k} \widehat{s}_{k 0}\right) \\
\text { s.t. } \quad & \operatorname{pro}\left(\frac{\sum_{k=1}^{K} W_{k} \widehat{s}_{k j}}{\left(\sum_{d=1}^{D} V_{d}^{1} l_{d j}+b_{0}\right)} \leq 1\right) \geq 1-\gamma_{j}, \\
& j=1, \ldots, n \\
& \sum_{d=1}^{D} V_{d}^{1} l_{d 0}+b_{0}=1 \\
& W_{k}, V_{d}^{1} \geq 0, \quad k=1, \ldots, K, d=1, \ldots, D \\
& b_{0} \text { is free }
\end{aligned}
$$

In model (5), $\widehat{s}_{k j}$ is a stochastic variable representing the motivated payment is uncertain in the agent's perspective; pro denotes "probability" measurement of the corresponding constraints and $\gamma_{j}(j=1, \ldots, n)$ is a probability that the output/input ratio becomes more than 1 with a choice of weight multipliers. Thus, $\gamma_{j}$ can be considered as a risk criterion representing to what extent the agent can bear the risk. On the other hand, $1-\gamma_{j}$ indicates the probability of achieving the requirement. Note that the risk criterion $\gamma_{j}$ is a prescribed value that is measured on the range between 0 and 1 . When $\gamma_{j}=0$, it is required that the output/input ratio becomes no more than unity; contrarily when $\gamma_{j}=$ 1 , model (5) omits the requirement under any selection of weight multipliers. It is stated that the confidence level can be set according to the requirement of managerial practice, which is similar to the implication of $\beta_{j}$. Note also that " $E$ " indicates an expected value of the sum of weighted $\widehat{s}_{k j}(j=1, \ldots, n)$. Similar to model (2), model (5) can be transformed as a deterministic model. See Appendix A for detailed transformation process. Suppose $W_{k}^{*}, V_{d}^{1^{*}}$, and $b_{0}^{*}$ are the optimal solution of model (5) and the efficiency of the agent is defined as $E\left(\sum_{k=1}^{K} W_{k}^{*} \widehat{s}_{k 0}\right)$.

It is worth noting that, in order to obtain a higher performance, the agent has the incentive to adjust the level of effort to fit the payment motivated by the principal. Specifically, a higher payment may not induce a higher effort, whereas a lower payment may spur the agent to exert a higher effort contrarily. This is consistent with moral hazard in principal-agent literature.

\section{Incorporating the Performances of the Principal and the Agent}

In previous sections, we discuss the situation where the principal and the agent desire to optimize her/his efficiency independently. Since the motivated payment is one of the output classifications of the agent and one of the input classifications of the principal, an inner linkage is formed between two parties, which directly affects their efficiencies simultaneously. A question arises on how to characterize the linkage between two parties.

In some practices, the agents manage the firms based on the payments from the principals and have the incentive to make their effort levels appropriate to the payments. The more the payments, the higher effort they may exert. In this regard, we can make an identification that they work in a cooperative manner and desire to improve their efficiencies simultaneously. In other cases, one party is assumed to be the leader in the principal-agent relationship. That is, the party has the priority to optimize the performance, and the performance of the other party is optimized subject to the requirement that the leader's efficiency holds constant. We will depict the two situations in detail.

3.1. Cooperative Model in Deterministic Scenario. First, we characterize the linkage between the principal and the agent in the context of cooperative situation when the input-output bundle is deterministic. On the basis of model (1) and model (4), we propose the following model:

$$
\begin{aligned}
e_{0}^{c}=\max & \frac{1}{2}\left(\sum_{r=1}^{R} U_{r} y_{r 0}+\sum_{k=1}^{K} W_{k} s_{k 0}\right) \\
\text { s.t. } & \frac{\sum_{r=1}^{R} U_{r} y_{r j}}{\left(\sum_{k=1}^{K} \widetilde{W}_{k} s_{k j}+\sum_{i=1}^{I} V_{i}^{2} x_{i j}\right)} \leq 1, \\
& \frac{\sum_{k=1}^{K} W_{k} s_{k j}}{\left(\sum_{d=1}^{D} V_{d}^{1} l_{d j}+b_{0}\right)} \leq 1, \quad j=1, \ldots, n \\
& \sum_{k=1}^{K} \widetilde{W}_{k} s_{k 0}+\sum_{i=1}^{I} V_{i}^{2} x_{i 0}=1 \\
& \sum_{d=1}^{D} V_{d}^{1} l_{d 0}+b_{0}=1 \\
& U_{r}, W_{k}, \widetilde{W}_{k}, V_{i}^{2}, V_{d}^{1} \geq 0, \\
& r=1, \ldots, R, \\
& k=1, \ldots, K, \\
& i=1, \ldots, I, \\
& d=1, \ldots, D \\
& b_{0}, i s f r e e
\end{aligned}
$$


where the objective is to maximize the arithmetic average efficiency of the principal and the agent. Note that $s_{k j}(k=$ $1, \ldots, K)$ have dual roles: outputs for the agent and inputs for the principal. This implies that the two parties have inner conflicts and cannot be mediated. Since both parties have the incentive to simultaneously improve the efficiencies, a tradeoff can occur that the principal offers an appropriate payment motivating the agent and the agent also exerts appropriate effort fitting the payment. In this way, any party can benefit the other with the desire to optimize the performances and consequently improve the efficiency of the firm with the principal-agent relationship.

The efficiencies of the principal and the agent are $e_{0}^{p c}=$ $\sum_{r=1}^{R} U_{r}^{*} y_{r 0}$ and $e_{0}^{a c}=\sum_{k=1}^{K} W_{k}^{*} s_{k 0}$ based on the optimal solution of $U_{r}^{*}, W_{k}^{*}, \widetilde{W}_{k}^{*}, V_{i}^{2 *}, V_{d}^{1^{*}}$, and $b_{0}^{*}$.

3.2. Cooperative Model in Stochastic Scenario. Similar to model (6), we propose the following model to illustrate the influence of the uncertain outputs and payments on the efficiencies. On the basis of model (3) and model (5), we propose the following model:

$$
\begin{aligned}
& e_{0}^{c s}=\max \frac{1}{2}\left(E\left(\sum_{r=1}^{R} U_{r} \widehat{y}_{r 0}\right)+E\left(\sum_{k=1}^{K} W_{k} \widehat{s}_{k 0}\right)\right) \\
& \text { s.t. } \quad \operatorname{pro}\left(\frac{\sum_{r=1}^{R} U_{r} \widehat{y}_{r j}}{\left(\sum_{k=1}^{K} \widetilde{W}_{k} \widehat{s}_{k j}+\sum_{i=1}^{I} V_{i}^{2} x_{i j}\right)} \leq 1\right) \\
& \geq 1-\beta_{j}, \quad j=1, \ldots, n \\
& \operatorname{pro}\left(\frac{\sum_{k=1}^{K} W_{k} \widehat{s}_{k j}}{\left(\sum_{d=1}^{D} V_{d}^{1} l_{d j}+b_{0}\right)} \leq 1\right) \geq 1-\gamma_{j} \text {, } \\
& j=1, \ldots, n \\
& E\left(\sum_{k=1}^{K} \widetilde{W}_{k} \widehat{s}_{k 0}\right)+\sum_{i=1}^{I} V_{i}^{2} x_{i 0}=1 \\
& \sum_{d=1}^{D} V_{d}^{1} l_{d o}+b_{0}=1 \\
& U_{r}, W_{k}, \widetilde{W}_{k}, V_{i}^{2}, V_{d}^{1} \geq 0, \\
& r=1, \ldots, R, \\
& k=1, \ldots, K, \\
& i=1, \ldots, I \text {, } \\
& d=1, \ldots, D \\
& b_{0} \text { is free }
\end{aligned}
$$

In model (7), the principal and the agent are assumed to face the uncertainty simultaneously, and $\beta$ and $\gamma$ represent their risk criterions, respectively. If only one of the parties is risk preferred or averse and the other is risk neutral, we can adjust the criterion correspondingly. For example, if $\beta_{j}=0$, it is required that $1-\beta_{j}$ in the first constraint is replaced by 1 while holding the other constraints constant. In some applications, the agent does not have the incentive to earn an uncertain payment from the principal; we can omit the risk criterion of the agent by replacing $1-\gamma_{j}$ in model (7) with a constant 1 .

It is worth noting that the efficiencies of both parties are affected by the risk criterions. Specifically, the risk criterion of a party can affect the performance of the other and vice versa. As we mentioned above, given that the principal desires to offer more payment to induce higher effort from the agent, the agent has to face the risk not only from his own attitude to risk but also from the principal's pursuing for more profits. This can be well illustrated from model (7) by the influences of $1-\beta_{j}$ and $1-\gamma_{j}$ on efficiencies.

In addition, the agent can also have the intention to better control the effort level $b_{0}$ in order to adapt the variance of the input-output vectors. Thus, the effort is also affected by the level of risk criterions, $\beta$ and $\gamma$.

Similar to model (2), model (7) can be transformed as a deterministic model. See Appendix A for detailed transformation process. Solve model (7) and we obtain the optimal solution $\left(U_{r}^{*}, W_{k}^{*}, \widetilde{W}_{k}^{*}, V_{i}^{2 *}, V_{d}^{1^{*}}\right.$, and $\left.b_{0}^{*}\right)$, the efficiencies of the principal and the agent are $e_{0}^{p \mathcal{c}^{\mathcal{S}}}=E\left(\sum_{r=1}^{R} U_{r}^{*} \hat{y}_{r 0}\right)$ and $e_{0}^{a c s}=E\left(\sum_{k=1}^{K} W_{k}^{*} \widehat{s}_{k 0}\right)$, respectively. Different from model (6), model (7) characterizes the influence of the uncertain payments and outputs on the performance and well depicts the influence on the effort level change.

3.3. Noncooperative Model. One form of a noncooperative game is characterized by the leader-follower assumption. In this situation, the performance of the leader is more important, and the efficiency of the other party (follower) is evaluated, subject to the leader maintaining its efficiency [17]. In subsections, we consider noncooperative conditions from the principal's and the agent's perspectives in which she/he dominates the system, respectively.

3.3.1. The Principal as the Leader. If the principal is assumed to be the leader, the efficiency for the principal can be calculated using model (3). Once we obtain the efficiency for the principal, the agent will only consider that the efficiency score of the principal remains $e_{0}^{p^{s *}}$. The model for computing the agent's efficiency, $e_{0}^{p a s}$, can be expressed as

$$
\begin{array}{rl}
e_{0}^{p a s}=\max & E\left(\sum_{k=1}^{K} W_{k} \widehat{s}_{k 0}\right) \\
\text { s.t. } \quad & \operatorname{pro}\left(\frac{\sum_{k=1}^{K} W_{k} \widehat{s}_{k j}}{\left(\sum_{d=1}^{D} V_{d}^{1} l_{k j}+b_{0}\right)} \leq 1\right) \geq 1-\gamma_{j}, \\
\sum_{d=1}^{D} V_{d}^{1} l_{d 0}+b_{0}=1 & j=1, \ldots, n
\end{array}
$$




$$
\begin{aligned}
& E\left(\sum_{r=1}^{R} U_{r} \widehat{y}_{r 0}\right) \\
& \quad-e_{0}^{p s^{*}}\left(E\left(\sum_{k=1}^{K} W_{k} \widehat{s}_{k 0}\right)+\sum_{i=1}^{I} V_{i}^{2} x_{i 0}\right)=0 \\
& \operatorname{pro}\left(\frac{\sum_{r=1}^{R} U_{r} \widehat{y}_{r j}}{\left(\sum_{k=1}^{K} W_{k} \widehat{s}_{k j}+\sum_{i=1}^{I} V_{i}^{2} x_{i j}\right)} \leq 1\right) \\
& \geq 1-\beta_{j}, \quad j=1, \ldots, n \\
& U_{r}, V_{i}^{2}, W_{k}, V_{d}^{1} \geq 0, \\
& r=1, \ldots, R, \\
& i=1, \ldots, I, \\
& k=1, \ldots, K \\
& d=1, \ldots, D
\end{aligned}
$$

The objective of model (8) is to maximize the agent's efficiency while ensuring that the optimal efficiency of the principal is guaranteed. The optimum value $e_{0}^{p a s^{*}}$ is the optimum efficiency of the agent. Similar to model (2), model (8) can be transformed as a deterministic model. See Appendix A for detailed transformation process.

3.3.2. The Agent as the Leader. In a similar manner, if the agent is assumed to be the leader, the efficiency for the agent can be calculated using model (5). Then, the model for computing the principal's efficiency can be expressed as

$$
\begin{aligned}
e_{0}^{a p s}=\max & E\left(\sum_{r=1}^{R} U_{r} \widehat{y}_{r 0}\right) \\
\text { s.t. } & \operatorname{pro}\left(\frac{\sum_{k=1}^{K} W_{k} \widehat{s}_{k j}}{\left(\sum_{d=1}^{D} V_{d}^{1} l_{k j}+b_{0}\right)} \leq 1\right) \geq 1-\gamma_{j}, \\
& E\left(\sum_{k=1}^{K} W_{k} \widehat{s}_{k 0}\right)-e_{0}^{a s *}\left(\sum_{d=1}^{D} V_{d}^{1} l_{d 0}+b_{0}\right)=0 \\
& \operatorname{pro}\left(\frac{\sum_{r=1}^{R} U_{r} \widehat{y}_{r j}}{\left(\sum_{k=1}^{K} W_{k} \widehat{s}_{k j}+\sum_{i=1}^{I} V_{i}^{2} x_{i j}\right)} \leq 1\right) \\
& \geq 1-\beta_{j}, \quad j=1, \ldots, n \\
& E\left(\sum_{k=1}^{K} W_{k} \widehat{s}_{k 0}\right)+\sum_{i=1}^{I} V_{i}^{2} x_{i 0}=1 \\
& U_{r}, V_{i}^{2}, W_{k}, V_{d}^{1} \geq 0, \\
r & =1, \ldots, R, \\
& i=1, \ldots, I, \\
& k=1, \ldots, K, \\
& d=1, \ldots, D
\end{aligned}
$$

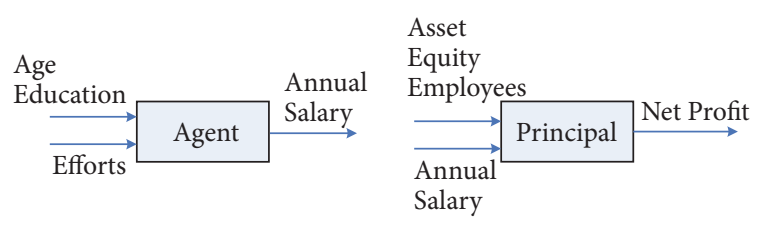

Figure 2: The inputs and outputs.

The objective of model (9) is to maximize the principal's efficiency while ensuring that the optimal efficiency of the agent is guaranteed. Similar to model (2), model (9) can be transformed as a deterministic model. See Appendix A for detailed transformation process.

\section{Empirical Analysis}

In this section, we empirically test the prediction of the relations between uncertainty and efficiency. We also investigate how such uncertainties affect the effort level of the agent.

4.1. Case Description. Due to the availability of the data, we collect the data of 16 real estate companies in China from the 2012 China Stock Market Financial Statements Database and China Listed Firm's Corporate Governance Research Database provided by the CSMAR. We select the asset (¥millions), equity (¥millions), and numbers of employees as the inputs and net profit (¥millions) as the output of the principal, which is similar to Seiford and Zhu [18] and Liang et al. [17].

As to the top management team (the agent), there is a large empirical management literature that investigates the role of human capital on organizational outcomes [19-23]. It is relatively uncontroversial to claim that human capital, in terms of both education background and experience, is associated with superior firm performance [19]. Entrepreneurship scholars have demonstrated that the quality of the team's past experience benefits their firm [24-26]. In this study, we take the stock of human capital as the human resources of the top management team. In particular, the average age of the executives represents social practice capability, and average educational year indicates the mind, learning ability, etc. In addition, the annual salary of management (ASM, ¥millions) is the motivated payment from the principal. The inputs and outputs of the principal and the agent can be reported in Figure 2, and the descriptive statistics for the data set are summarized in Table 1.

Following Land et al. [7], we assume that the observed outcomes and motivated payments coincide with their mathematical expectations; i.e., $E\left(\widehat{y}_{r j}\right)=\bar{y}_{r j}=y_{r j}$ and $E\left(\widehat{s}_{k j}\right)=$ $\bar{s}_{k j}=s_{k j}(j=1, \ldots, n)$. Thus, these estimated outcomes and payments are considered as the expected outcomes and payments. The standard deviations of outcomes and payments for each DMU can be obtained by using the data of estimated values during five successive years (2008-2012). The mean values and standard deviations of estimated outcomes and payments are shown in Table 2. 
TABLE 1: The descriptive statistics for the data set.

\begin{tabular}{lccccc}
\hline Variables & & Max & Min & Mean & Std. Dev \\
\hline$x_{1}$ & Asset (¥millions) & 70864 & 2868 & 17945 & 17383 \\
$x_{2}$ & Equity (¥millions) & 13952 & 1138 & 5531 & 4314 \\
$x_{3}$ & Numbers of employees & 6513 & 224 & 1847 & 1886 \\
$l_{1}$ & Average age & 54.86 & 43.89 & 49.44 & 3.20 \\
$l_{2}$ & Average educational year & 6.32 & 0.40 & 2.16 \\
$s$ & Annual salary of management (¥millions) & 12.2169 & 1.9498 & 6.3145 \\
$y$ & Net profit (¥millions) & 1536.09 & 9.96 & 489.40 & 3.1050 \\
\hline
\end{tabular}

TABLE 2: Means and standard deviations of estimated outcomes and payments.

\begin{tabular}{|c|c|c|c|c|}
\hline \multirow{2}{*}{ DMUs } & \multicolumn{2}{|c|}{ Payments } & \multicolumn{2}{|c|}{ Outcomes } \\
\hline & Mean & Std. Dev & Mean & Std. Dev \\
\hline SZZY & 7.0302 & 1.4066 & 629.57 & 179.82 \\
\hline BAHRE & 6.1903 & 1.1817 & 194.1 & 123.55 \\
\hline OW & 12.2169 & 1.9564 & 778.05 & 259.24 \\
\hline RONG AN & 4.23 & 2.3957 & 424.27 & 318.88 \\
\hline ZHONG TIAN & 1.9498 & 3.0938 & 49.83 & 227.06 \\
\hline JINKE & 8.6793 & 9.7698 & 163.59 & 455.94 \\
\hline TAI HE & 4.026 & 1.3016 & 315.55 & 99.80 \\
\hline GUANG YU & 3.365 & 1.5490 & 271.14 & 79.65 \\
\hline SHOU CHUANG & 7.515 & 1.6744 & 746.75 & 151.92 \\
\hline $\mathrm{CHJK}$ & 3.7216 & 0.6749 & 9.96 & 43.26 \\
\hline TJFDCH & 3.8593 & 1.0448 & 337.19 & 116.03 \\
\hline TIAN HONG & 11.6241 & 12.0041 & 1536.09 & 525.37 \\
\hline WAN YE & 3.2627 & 0.5278 & 110.05 & 112.01 \\
\hline $\mathrm{DMCH}$ & 5.6539 & 2.2278 & 253.66 & 470.30 \\
\hline SHI MAO & 9.6582 & 3.5058 & 1401.03 & 596.83 \\
\hline BEI CHEN & 8.0502 & 1.8806 & 609.56 & 155.68 \\
\hline
\end{tabular}

4.2. Computational Results. To illustrate the rationality of the proposed stochastic DEA approach, we first compare the computational results of 16 DMUs from the deterministic models and our proposed models, i.e., model (1); model (2) and model (3); model (4) and model (5). Evidently, the application of models (2), (3), and (5) will inevitably involve the determination of risk criterion $\beta_{j}$ and $\gamma_{j}(j=1, \ldots, 16)$. In the related studies, $\beta_{j}$ and $\gamma_{j}$ are commonly set as 0.05 $[7,14]$. In order to investigate the impacts of $\beta_{j}$ and $\gamma_{j}$ on efficiencies and the effort level, we further apply two sets of values; i.e., $\beta_{j}, \gamma_{j}=0.1$ and $\beta_{j}, \gamma_{j}=0.2$. Tables 3 and 4 report the overall computational results.

The following is found in Table 3:

(1) In model (2) and model (3), the efficiencies of the principals are increasing in the risk criterion $(\beta)$. A possible reason is that the stochastic DEA models are to replace "hard" frontiers of deterministic DEA with "soft" frontiers. This also demonstrates that the risk criterion can have influence on the efficiency evaluation in the context of the principal and the agent. If such risk attitude is ignored, the resulted performances may not be practical.

(2) It is worth noting that the results of model (1) are the same as model (2) with $\beta=0.5$. The efficiency results are also shown in Table 3. This indicates that the deterministic model is a special case of the proposed stochastic model. Moreover, given the risk criterion is lower than 0.5 , i.e., $\beta=0.05,0.1,0.2$, the efficiencies of the principals in model (2) is lower than that in model (1).

(3) If $\beta<0.2$, the efficiency of the principal in model (3) is lower than that in model (1). However, if $\beta=0.2$, it does not hold because the efficiencies of 5 principals in model (3) are larger than that in model (1). A possible reason is that the payments are also viewed as stochastic variables, which induces the risk criterion on stochastic payments to have influence on the efficiency evaluation. In addition, in model (3), when $\beta=$ 0.2 , three principals are judged as extremely efficient (i.e., the efficiencies of these principals are larger than 1). The reason for these extremely efficient principals 
TABLE 3: The efficiencies of the principals.

\begin{tabular}{lcccccccc}
\hline \multirow{2}{*}{ DMUs } & Model (1) & \multicolumn{3}{c}{ Model (2) } & \multicolumn{3}{c}{ Model (3) } \\
& & $\beta=0.05$ & $\beta=0.1$ & $\beta=0.2$ & $\beta=0.5$ & $\beta=0.05$ & $\beta=0.1$ & $\beta=0.2$ \\
\hline SZZY & 1.0000 & 0.6803 & 0.7323 & 0.8065 & 1.0000 & 0.8585 & 0.9299 \\
BAHRE & 1.0000 & 0.4885 & 0.5510 & 0.6516 & 1.0000 & 0.5428 & 0.6073 & 0.7023 \\
OW & 0.6115 & 0.2843 & 0.3241 & 0.3897 & 0.6115 & 0.4460 & 0.4951 & 0.5708 \\
RONG AN & 1.0000 & 0.4472 & 0.5097 & 0.6130 & 1.0000 & 0.7271 & 0.8104 & 0.9402 \\
ZHONG TIAN & 0.2692 & 0.1177 & 0.1464 & 0.1770 & 0.2692 & 0.1928 & 0.2159 & 0.2524 \\
JINKE & 0.2018 & 0.1231 & 0.1417 & 0.1589 & 0.2018 & 0.1525 & 0.1724 & 0.1927 \\
TAI HE & 0.8221 & 0.3601 & 0.4445 & 0.5372 & 0.8221 & 0.5894 & 0.6598 & 0.7709 \\
GUANG YU & 0.7994 & 0.4060 & 0.4723 & 0.5552 & 0.7994 & 0.5774 & 0.6427 & 0.7441 \\
SHOU CHUANG & 0.7965 & 0.4303 & 0.4850 & 0.5728 & 0.7965 & 0.6433 & 0.7080 & 0.8057 \\
CHJK & 0.0332 & 0.0216 & 0.0238 & 0.0264 & 0.0332 & 0.0237 & 0.0271 & 0.0300 \\
TJFDCH & 0.7907 & 0.4206 & 0.4762 & 0.5666 & 0.7907 & 0.6371 & 0.7002 & 0.7906 \\
TIAN HONG & 1.0000 & 0.5636 & 0.6316 & 0.7393 & 1.0000 & 0.8555 & 0.9415 & 1.0715 \\
WAN YE & 0.3435 & 0.2077 & 0.2295 & 0.2625 & 0.3435 & 0.2853 & 0.3129 & 0.3494 \\
DMCH & 0.4626 & 0.2469 & 0.2920 & 0.3369 & 0.4626 & 0.3332 & 0.3726 & 0.4320 \\
SHI MAO & 1.0000 & 0.5880 & 0.6471 & 0.7365 & 1.0000 & 0.9391 & 1.0336 \\
BEI CHEN & 0.5612 & 0.3134 & 0.3475 & 0.3998 & 0.5612 & 0.4902 & 0.5395 & 0.1762 \\
\hline
\end{tabular}

TABLE 4: The efficiencies and effort levels of the agents.

\begin{tabular}{|c|c|c|c|c|c|c|c|c|c|c|}
\hline \multirow{3}{*}{ DMUs } & \multirow{2}{*}{\multicolumn{2}{|c|}{ Model (4) }} & \multicolumn{8}{|c|}{ Model (5) } \\
\hline & & & \multicolumn{2}{|c|}{$\gamma=0.05$} & \multicolumn{2}{|c|}{$\gamma=0.1$} & \multicolumn{2}{|c|}{$\gamma=0.2$} & \multicolumn{2}{|c|}{$\gamma=0.5$} \\
\hline & $e^{a}$ & $b_{0}$ & $e^{a s}$ & $b_{0}$ & $e^{a s}$ & $b_{0}$ & $e^{a s}$ & $b_{0}$ & $e^{a s}$ & $b_{0}$ \\
\hline SZZY & 1.0000 & -2.5972 & 0.7524 & -2.5821 & 0.7961 & -2.5877 & 0.8561 & -2.5808 & 1.0000 & -2.5972 \\
\hline BAHRE & 0.5231 & 0.9651 & 0.1973 & 1.0000 & 0.2294 & 1.0000 & 0.2852 & 1.0000 & 0.5231 & 0.9651 \\
\hline OW & 1.0000 & 0.6020 & 0.3894 & 1.0000 & 0.4527 & 1.0000 & 0.5628 & 1.0000 & 1.0000 & 0.6020 \\
\hline RONG AN & 0.3641 & -0.7547 & 0.1370 & -4.1349 & 0.1590 & -3.8026 & 0.1974 & -3.2253 & 0.3641 & -0.7547 \\
\hline ZHONG TIAN & 0.1709 & -0.7684 & 0.0664 & -4.3460 & 0.0768 & -3.9836 & 0.0948 & -3.3596 & 0.1709 & -0.7684 \\
\hline JINKE & 0.7522 & -0.7559 & 0.2887 & -4.2470 & 0.3346 & -3.8989 & 0.4140 & -3.2970 & 0.7522 & -0.7559 \\
\hline TAI HE & 0.3342 & 0.9479 & 0.1283 & 1.0000 & 0.1492 & 1.0000 & 0.1855 & 1.0000 & 0.3342 & 0.9479 \\
\hline GUANG YU & 0.3472 & -0.8999 & 0.2145 & -8.1405 & 0.2344 & -7.0447 & 0.2639 & -5.4198 & 0.3472 & -0.8999 \\
\hline SHOU CHUANG & 0.6151 & 1.0000 & 0.2396 & 1.0000 & 0.2784 & 1.0000 & 0.3462 & 1.0000 & 0.6151 & 1.0000 \\
\hline CHJK & 1.0000 & -380.60 & 0.7702 & -167.87 & 0.8116 & -178.12 & 0.8678 & -199.02 & 1.0000 & -380.60 \\
\hline TJFDCH & 0.3159 & 1.0000 & 0.1230 & 1.0000 & 0.1430 & 1.0000 & 0.1778 & 1.0000 & 0.3159 & 1.0000 \\
\hline TIAN HONG & 1.0000 & -2.7161 & 0.3705 & -1.0574 & 0.4307 & -0.9567 & 0.5355 & -1.0368 & 1.0000 & -2.7161 \\
\hline WAN YE & 0.4609 & 0.6686 & 0.3406 & -0.1743 & 0.3616 & -0.0276 & 0.3905 & 0.1752 & 0.4609 & 0.6686 \\
\hline $\mathrm{DMCH}$ & 0.4763 & 0.9620 & 0.1802 & 1.0000 & 0.2095 & 1.0000 & 0.2605 & 1.0000 & 0.4763 & 0.9620 \\
\hline SHI MAO & 1.0000 & -758.15 & 0.6261 & -734.13 & 0.6828 & -666.14 & 0.7663 & -989.94 & 1.0000 & -758.15 \\
\hline BEI CHEN & 0.6589 & 1.0000 & 0.2566 & 1.0000 & 0.2983 & 1.0000 & 0.3708 & 1.0000 & 0.6589 & 1.0000 \\
\hline
\end{tabular}

may be due to the risk criterion $(\beta)$ (as we know, in deterministic DEA approaches, the efficiency scores are commonly restricted to a value no more than unit. However, in stochastic DEA models, this stochastic efficiency can be released by using risk criterion $(\beta)$ and [27]). This indicates that the proposed model may have relatively higher efficiency discriminating power than that of the deterministic DEA model. Furthermore, the stochastic DEA model can identify extremely efficient principals, which cannot be done under deterministic approach [28].

(4) The efficiencies of the principals in model (3) are larger than that in model (2). It indicates that the stochastic characteristic of the payments the principal motivates the agent can be beneficial to increase her own efficiency.

The following is found in Table 4: 
TABLE 5: The efficiency results.

\begin{tabular}{|c|c|c|c|c|c|c|c|c|c|c|}
\hline \multirow{4}{*}{ DMUs } & \multirow{3}{*}{\multicolumn{3}{|c|}{$\begin{array}{c}\text { Deterministic scenario } \\
\text { Model (6) } \\
\text { Cooperation }\end{array}$}} & \multicolumn{7}{|c|}{ Stochastic scenario } \\
\hline & & & & \multirow{2}{*}{\multicolumn{3}{|c|}{$\begin{array}{c}\text { Model (7) } \\
\text { Cooperation }\end{array}$}} & \multirow{2}{*}{\multicolumn{2}{|c|}{$\begin{array}{c}\text { Model (8) } \\
\text { Principal as leader }\end{array}$}} & \multirow{2}{*}{\multicolumn{2}{|c|}{$\begin{array}{c}\text { Model (9) } \\
\text { Agent as leader }\end{array}$}} \\
\hline & & & & & & & & & & \\
\hline & $e^{p c}$ & $\operatorname{Rank}^{\mathrm{a}}$ & $e^{a c}$ & $e^{p c s}$ & $\operatorname{Rank}^{\mathrm{b}}$ & $e^{a c s}$ & $e^{p s}$ & $e^{p a s}$ & $e^{a p s}$ & $e^{a s}$ \\
\hline$\overline{S Z Z Y}$ & 1.0000 & 1 & 0.8543 & 0.8494 & 3 & 0.6148 & 0.8585 & 0.7524 & 0.4049 & 0.7524 \\
\hline BAHRE & 1.0000 & 2 & 0.0035 & 0.5428 & 8 & 0.0698 & 0.5428 & 0.1973 & 0.3282 & 0.1973 \\
\hline OW & 0.4390 & 11 & 1.0000 & 0.4123 & 11 & 0.3894 & 0.4460 & 0.3894 & 0.2047 & 0.3894 \\
\hline RONG AN & 1.0000 & 3 & 0.2244 & 0.7271 & 4 & 0.0921 & 0.7271 & 0.1370 & 0.3090 & 0.1370 \\
\hline ZHONG TIAN & 0.2672 & 14 & 0.1091 & 0.1928 & 14 & 0.0464 & 0.1928 & 0.0664 & 0.1053 & 0.0664 \\
\hline JINKE & 0.1299 & 15 & 0.7522 & 0.1220 & 15 & 0.2887 & 0.1525 & 0.2887 & 0.1003 & 0.2887 \\
\hline TAI HE & 0.8165 & 6 & 0.2126 & 0.5894 & 7 & 0.0895 & 0.5894 & 0.1283 & 0.2632 & 0.1283 \\
\hline GUANG YU & 0.7942 & 7 & 0.2115 & 0.5216 & 9 & 0.2145 & 0.5774 & 0.2145 & 0.2523 & 0.2145 \\
\hline SHOU CHUANG & 0.6850 & 9 & 0.6151 & 0.6433 & 5 & 0.2396 & 0.6433 & 0.2396 & 0.2017 & 0.2396 \\
\hline $\mathrm{CHJK}$ & 0.0185 & 16 & 1.0000 & 0.0173 & 16 & 0.7702 & 0.0237 & 0.7702 & 0.0208 & 0.7702 \\
\hline TJFDCH & 0.7907 & 8 & 0.2187 & 0.6371 & 6 & 0.0773 & 0.6371 & 0.1230 & 0.2174 & 0.1230 \\
\hline TIAN HONG & 0.9110 & 5 & 1.0000 & 0.8555 & 2 & 0.3705 & 0.8555 & 0.3705 & 0.2608 & 0.3705 \\
\hline WAN YE & 0.3080 & 13 & 0.3986 & 0.2184 & 13 & 0.3406 & 0.2853 & 0.3406 & 0.1358 & 0.3406 \\
\hline $\mathrm{DMCH}$ & 0.3093 & 12 & 0.4763 & 0.2904 & 12 & 0.1802 & 0.3332 & 0.1802 & 0.1966 & 0.1802 \\
\hline SHI MAO & 1.0000 & 4 & 1.0000 & 0.9391 & 1 & 0.6261 & 0.9391 & 0.6261 & 0.2696 & 0.6261 \\
\hline BEI CHEN & 0.5220 & 10 & 0.6589 & 0.4902 & 10 & 0.2566 & 0.4902 & 0.2566 & 0.1554 & 0.2566 \\
\hline
\end{tabular}

${ }^{a}$ The efficiency ranks of the principals in deterministic scenario.

${ }^{b}$ The efficiency ranks of the principals in stochastic scenario.

TABLE 6: The effort levels.

\begin{tabular}{|c|c|c|c|c|}
\hline DMUs & $\begin{array}{c}\text { Model (6) } \\
b_{0}\end{array}$ & $\begin{array}{c}\text { Model (7) } \\
b_{0} \\
\end{array}$ & $\begin{array}{c}\text { Model (8) } \\
b_{0}\end{array}$ & $\begin{array}{c}\text { Model (9) } \\
b_{0}\end{array}$ \\
\hline SZZY & -3.1238 & -3.5660 & -2.9427 & -2.5821 \\
\hline BAHRE & -2.1176 & -1.9675 & 1.0000 & 1.0000 \\
\hline OW & 0.5046 & 1.0000 & 1.0000 & 1.0000 \\
\hline RONG AN & -3.3452 & -4.2096 & -4.1349 & -4.1349 \\
\hline ZHONG TIAN & -4.7168 & -6.6646 & -4.3460 & -4.3460 \\
\hline JINKE & -0.7559 & -4.2470 & -4.2470 & -4.2470 \\
\hline TAI HE & 0.0034 & 0.0503 & 1.0000 & 1.0000 \\
\hline GUANG YU & -192.06 & -8.1405 & -8.1405 & -8.1405 \\
\hline SHOU CHUANG & 1.0000 & 1.0000 & 1.0000 & 1.0000 \\
\hline CHJK & -807.85 & -1132.9 & -907.5819 & -167.87 \\
\hline TJFDCH & 0.5776 & 0.4252 & 1.0000 & 1.0000 \\
\hline TIAN HONG & -1.2980 & -2.5103 & -2.4893 & -1.0574 \\
\hline WAN YE & -2.3651 & -0.1743 & -0.1743 & -0.1743 \\
\hline $\mathrm{DMCH}$ & 0.9620 & 1.0000 & 1.0000 & 1.0000 \\
\hline SHI MAO & -2337.9 & -1347.0 & -17955.6 & -734.13 \\
\hline BEI CHEN & 1.0000 & 1.0000 & 1.0000 & 1.0000 \\
\hline
\end{tabular}

(1) The efficiencies of the agents in Model (5) are increasing in the risk criterion $\gamma$.

(2) It is worth noting that the results of model (4) are same as model (5) when $\gamma=0.5$. Consequently, given the risk criterion is lower than 0.5 , i.e., $\gamma=0.05$, $0.1,0.2$, the efficiencies of the agents in model (4) are lower than that in model (5).

(3) In model (5), except for CHJK, TIAN HONG and SHI MAO, the agent's effort level $b_{0}$ will increase or hold constant when the risk criterion $\gamma$ increases. This indicates that for most of the agents, the effort level is positively related to the risk criterion.
To further investigate the influences of the risk criterion $\beta$ and $\gamma$ on the efficiencies of both parties and the effort levels of the agents in the situations where two parties cooperating or non-cooperating, we compare the computational results of the deterministic models and our proposed stochastic models. Given the chosen risk levels of two parties, i.e., $\beta_{j}=$ 0.05 and $\gamma_{j}=0.05$, the results are displayed in Tables 5 and 6 .

The following is found in Tables 5 and 6:

(1) In cooperative situation, except for BAHRE and GUANG YU, the efficiencies of the principals and the agents in model (7) are lower than that in model (6).

(2) The efficiencies of the principals in model (8) are larger than that in model (7) and (9) respectively. 
TABLE 7: Stochastic efficiencies under different standard deviations ${ }^{\mathrm{a}}$.

\begin{tabular}{|c|c|c|c|c|c|c|c|c|}
\hline \multirow{3}{*}{ DMUs } & \multicolumn{8}{|c|}{ Model (7) } \\
\hline & \multicolumn{2}{|c|}{$-5 \%$} & \multicolumn{2}{|c|}{$-1 \%$} & \multicolumn{2}{|c|}{$1 \%$} & \multicolumn{2}{|c|}{$5 \%$} \\
\hline & $e^{p c s}$ & $e^{a c s}$ & $e^{p c s}$ & $e^{a c s}$ & $e^{p c s}$ & $e^{a c s}$ & $e^{p c s}$ & $e^{a c s}$ \\
\hline SZZY & 0.8578 & 0.6227 & 0.8510 & 0.6164 & 0.8478 & 0.6132 & 0.8415 & 0.6070 \\
\hline BAHRE & 0.5562 & 0.0748 & 0.5454 & 0.0708 & 0.5401 & 0.0689 & 0.5299 & 0.0652 \\
\hline OW & 0.4131 & 0.4021 & 0.4124 & 0.3919 & 0.4121 & 0.3870 & 0.4115 & 0.3776 \\
\hline RONG AN & 0.7338 & 0.0952 & 0.7284 & 0.0927 & 0.7258 & 0.0915 & 0.7207 & 0.0891 \\
\hline ZHONG TIAN & 0.1945 & 0.0479 & 0.1931 & 0.0467 & 0.1924 & 0.0461 & 0.1911 & 0.0450 \\
\hline JINKE & 0.1223 & 0.2979 & 0.1221 & 0.2905 & 0.1220 & 0.2869 & 0.1218 & 0.2800 \\
\hline TAI HE & 0.5948 & 0.0925 & 0.5905 & 0.0901 & 0.5884 & 0.0889 & 0.5843 & 0.0866 \\
\hline GUANG YU & 0.5226 & 0.2187 & 0.5218 & 0.2153 & 0.5214 & 0.2137 & 0.5206 & 0.2105 \\
\hline $\mathrm{SHCH}$ & 0.6445 & 0.2473 & 0.6435 & 0.2411 & 0.6430 & 0.2381 & 0.6421 & 0.2322 \\
\hline CHJK & 0.0174 & 0.7792 & 0.0173 & 0.7720 & 0.0173 & 0.7685 & 0.0173 & 0.7615 \\
\hline TJFDCH & 0.6436 & 0.0799 & 0.6384 & 0.0778 & 0.6359 & 0.0768 & 0.6309 & 0.0749 \\
\hline TIAN HONG & 0.8571 & 0.3826 & 0.8558 & 0.3729 & 0.8551 & 0.3682 & 0.8539 & 0.3592 \\
\hline WAN YE & 0.2188 & 0.3451 & 0.2184 & 0.3415 & 0.2183 & 0.3397 & 0.2179 & 0.3362 \\
\hline $\mathrm{DMCH}$ & 0.2910 & 0.1861 & 0.2905 & 0.1814 & 0.2903 & 0.1791 & 0.2899 & 0.1747 \\
\hline SHI MAO & 0.9409 & 0.6381 & 0.9394 & 0.6285 & 0.9387 & 0.6238 & 0.9373 & 0.6146 \\
\hline BEI CHEN & 0.4911 & 0.2650 & 0.4904 & 0.2582 & 0.4900 & 0.2550 & 0.4893 & 0.2488 \\
\hline
\end{tabular}

a $-5 \%,-1 \%, 1 \%$ and $5 \%$ denotes the scenarios of the standard deviations of outcomes and payments increase by $-5 \%,-1 \%, 1 \%$ and $5 \%$, respectively.

This indicates that the efficiency of the principal in the situation where she is a leader reaches the upper bound of the efficiency.

(3) The efficiencies of the agents in model (8) are equivalent to that in model (9). This clearly shows that although the agent is a follower, he can also reach the maximization of the efficiency by adjusting the effort level.

(4) The efficiencies of the agents in cooperative situation (model (7)) are lower than that in the situation where the principals are leaders (model (8)). It also implies that the agent has the incentive to possibly put himself in a favorable position by adjusting the effort level even if he is in the dominance of the principal. For example, the effort levels of the agents in the DMUs such as SZZY, BAHRE, RONG AN, ZHONG TIAN, TAI HE and TJFDCH, are larger than that in model (7), which gives a glimpse that they intend to raise the effort level as followers.

(5) The efficient DMUs in deterministic scenario are inefficient in stochastic scenario. For example, SZZY, BAHRE, RONG AN and SHI MAO are efficient (i.e., the efficiencies of these principals are 1) in deterministic scenario, whereas these DMUs are inefficient in stochastic scenario. More similar examples, see OW, $\mathrm{CHJK}$, TIAN HONG and SHI MAO (the efficient agents), etc.

In addition, to further illustrate the changes in relatively efficiency (e.g., rank orders), we compare the efficiency ranks of the deterministic model and the proposed stochastic model (i.e., the third and sixth columns in Table 5). It is found that the efficiency ranks of the principals in stochastic scenario are different from that in deterministic scenario. For example, BAHRE is ranked second in deterministic scenario, whereas this DMU is ranked eighth in stochastic scenario. More similar examples, see TIAN HONG, SHI MAO and SHOU CHUANG, etc. These results indicate that the relative efficiency changes after introducing uncertainty.

4.3. Sensitivity Analysis of the Standard Deviations of Outcomes and Payments. To further investigate impacts of the uncertain outputs and payments on the principal's and the agent's efficiencies, similar to Zha et al. [14], we in this subsection conduct the sensitivity analysis with respect to the standard deviations of outputs and payments.

In order to implement this analysis, four scenarios are considered with respect to the decrease and increase in the standard deviations of outcomes and payments by $1 \%$ and $5 \%$, respectively. The results of efficiency and the effort level under model (7) with $\beta, \gamma=0.05$ are reported in Tables 7 and 8.

The following is found in Tables 7 and 8:

(1) The efficiencies of the principal and the agent increase when the standard deviations of outcomes and payments decrease. That is, the larger the variations of outcomes and payments are, the lower the efficiencies are (models (8)-(9) have similar trends which can be seen in Appendix B).We take SZZY as an example to illustrate this point. In model (7), SZZY has gained the efficiency scores 0.8578 (the principal) and 0.6227 (the agent) when the standard deviation of its outcomes and payments decreases by $5 \%$; its efficiency then decreases with the standard deviation rising; when the standard deviation increase by $5 \%$, 
TABLE 8: The effort levels under different standard deviations.

\begin{tabular}{lcccc}
\hline \multirow{2}{*}{ DMUs } & \multicolumn{5}{c}{$b_{0}$} \\
& $-5 \%$ & $-1 \%$ & $1 \%$ & $5 \%$ \\
\hline SZZY & -3.5567 & -3.5536 & -3.5843 & -3.5785 \\
BAHRE & -1.9492 & -1.9635 & -1.9682 & -1.9801 \\
OW & 1.0000 & 1.0000 & 1.0000 & 1.0000 \\
RONG AN & -4.0279 & -4.1552 & -4.2253 & -4.4103 \\
ZHONG TIAN & -6.6535 & -6.5729 & -6.8636 & -7.1802 \\
JINKE & -4.1772 & -4.2334 & -4.2605 & -4.3127 \\
TAI HE & 0.0376 & 0.0466 & 0.0591 & -0.0297 \\
GUANG YU & -7.9101 & -8.0952 & -8.1856 & -8.3623 \\
SHCH & 1.0000 & 1.0000 & 1.0000 & 1.0000 \\
CHJK & -1099.8 & -1086.3 & -1134.5 & -1138.6 \\
TJFDCH & 0.4330 & 0.4267 & 0.4237 & 0.4170 \\
TIAN HONG & -2.4223 & -2.4981 & -2.5186 & -2.5781 \\
WAN YE & -0.1427 & -0.1680 & -0.1805 & -0.2050 \\
DMCH & 1.0000 & 1.0000 & 1.0000 & 1.0000 \\
SHI MAO & -1323.7 & -1339.8 & -1355.4 & -1414.6 \\
BEI CHEN & 1.0000 & 1.0000 & 1.0000 & 1.0000 \\
\hline
\end{tabular}

it has achieved the lowest efficiency scores 0.8415 (the principal) and 0.6070 (the agent). This indicates that the uncertainty levels of outcomes and payments significantly influence the stochastic performances of the principal and the agent.

(2) Except for SZZY, TAI HE, and CHJK, the effort levels of other agents decrease or remain constant with the increase of the standard deviations of the outcomes and payments (models (8)-(9) have similar trends which can be seen in Appendix B).

\section{Conclusions}

This paper examines the efficiencies of the principal and the agent by taking into consideration the uncertainties of the outcomes and motivated payments. To this end, stochastic DEA models based on chance constrained programming are presented. Based on the statistical theory, the stochastic DEA models can be successfully transformed into deterministic ones for ease of the solutions.

Based on the results of the empirical study, some findings and conclusions can be achieved. First, the uncertainties have significant impacts on efficiencies of the principal and the agent. This indicates that ignoring the uncertainties of the outcomes and payments in the process of performance evaluation would result in biased efficiency scores. It is noteworthy that the impacts of the outcomes and payments attribute to the decision makers' risk criterions and the standard deviations of estimated outcomes and payments. This in turn provides important implications for the management of motivated payments. On the one hand, the risk criterion directly affects the results of the principal's efficiency, which may directly influence how the principal designs incentive contract, i.e., paying uncertain compensations to the agent? This suggests that when measuring efficiency, a suitable risk criterion is required. On the other hand, the standard deviations of estimated outcomes and payments have great influences on the efficiencies of the principal and the agent. This implies that, in order to improve the principal and the agent's efficiencies, the uncertainty should be taken for better control. Second, if the outputs (outcomes) of the principal and the payments she motivates the agent are stochastic, the principal can have the advantage to increase the efficiency. Third, for most of the DMUs, the effort level of the agent increase or remain constant with increase of the risk criterion. This indicates that the effort level is positively related to the risk criterion. In addition, for most of the DMUs, the effort level remains constant or decreases with the increase of the standard deviations of outcomes and payments. This shows that the level of the uncertainty has significant influence on the agent's effort level. The more uncertain the outcomes and payments are, the less effort the agent exerts, which is described by hidden action in traditional principal-agent context.

We have three main methodological contributions in this work. First, the analytical framework and models are developed to measure the efficiencies of the agent and the principal in stochastic situation. Second, we innovatively characterize the effort level as a variable in DEA context. Third, we portray possible changes of efficiency and effort level when the principal and the agent encounter stochastic situation, which can help the principal design incentive strategy in stochastic situation.

The analysis is conducted by using the dataset in the year of 2012. An extension of this study is to apply a multipleyear panel data to describe the changes of effort level and provide more insights for the efficiencies of two parties. In addition, we only consider the uncertainties of the outcomes and payments in this study. On account of the limited data availability of economic condition, demographic change and other socio-economic, it is not clear whether and how the factors affect the uncertainty in the principal-agent setting. Further investigation on this issue can also extend our study and provide some interesting topics in future research.

\section{Data Availability}

We collect the data of 16 real estate companies in China from the 2012 China Stock Market Financial Statements Database and China Listed Firm's Corporate Governance Research Database provided by the CSMAR.

\section{Conflicts of Interest}

The authors declare that they have no conflicts of interest.

\section{Acknowledgments}

This work was supported by the Philosophy and Social Science Foundation of Jiangsu Higher Education Institutions of China (Grant no. 2018SJA0326), Natural Science Foundation of Jiangsu Higher Education Institutions of China (17KJB120007), National Natural Science Foundation 
of China (Grant nos. 71701102, 71701111, and 71671173), and Major International (Regional) Joint Research Projects (Grant no. 71520107002).

\section{Supplementary Materials}

A. Reformulation of DEA stochastic models. The constraints of model (2), including the stochastic process, can be rewritten as follows: B. Sensitivity analysis of the standard deviations of outcomes and payments. (Supplementary Materials)

\section{References}

[1] Y. Y. Kor, "Experience-Based Top Management Team Competence and Sustained Growth," Organization Science, vol. 14, no. 6, pp. 707-755, 2003.

[2] P. Herrmann and D. K. Datta, "Relationships between top management team characteristics and international diversification: An empirical investigation," British Journal of Management, vol. 16, no. 1, pp. 69-78, 2005.

[3] A. Srivastava, K. M. Bartol, and E. A. Locke, "Empowering leadership in management teams: Effects on knowledge sharing, efficacy, and performance," Academy of Management Journal (AMJ), vol. 49, no. 6, pp. 1239-1251, 2006.

[4] B. Holmstrom, "Moral hazard and observability," RAND Journal of Economics, vol. 10, no. 1, pp. 74-91, 1979.

[5] H. Zhang and S. Zenios, "A dynamic principal-agent model with hidden information: sequential optimality through truthful state revelation," Operations Research, vol. 56, no. 3, pp. 681-696, 2008.

[6] N. Obiekwe, Employee Motivation and Performance, 2016.

[7] K. C. Land, C. A. K. Lovell, and S. Thore, "Chance-constrained data envelopment analysis," Managerial and Decision Economics, vol. 14, no. 6, pp. 541-554, 1993.

[8] T. Sueyoshi, "Stochastic DEA for restructure strategy: An application to a japanese petroleum company," Omega , vol. 28, no. 4, pp. 385-398, 2000.

[9] B. Holmström and P. Milgrom, "Aggregation and linearity in the provision of intertemporal incentives," Econometrica, vol. 55, no. 2, pp. 303-328, 1987.

[10] C. Prendergast, "The Tenuous Tradeoff Between Risk and Incentives," National Bureau of Economic Research w7815, 2000.

[11] Z. He, S. Li, B. Wei, and J. Yu, "Uncertainty, risk, and incentives: Theory and evidence," Management Science, vol. 60, no. 1, pp. 206-226, 2014.

[12] W. W. Cooper, H. Deng, Z. Huang, and S. X. Li, "Chance constrained programming approaches to technical efficiencies and inefficiencies in stochastic data envelopment analysis," Journal of the Operational Research Society, vol. 53, no. 12, pp. 1347-1356, 2002.

[13] K. Vincová, "Using DEA models to measure efficiency," Biatec, vol. 13, no. 8, pp. 24-28, 2005.

[14] Y. Zha, L. Zhao, and Y. Bian, "Measuring regional efficiency of energy and carbon dioxide emissions in China: A chance constrained DEA approach," Computers \& Operations Research, vol. 66, pp. 351-361, 2016.

[15] L. A. Bebchuk and J. M. Fried, "Pay without Performance: Overview of the issues," Academy of Management Perspectives, vol. 20, no. 1, pp. 5-24, 2006.
[16] R. D. Banker, A. Charnes, and W. W. Cooper, "Some models for estimating technical and scale efficiencies in data envelopment analysis," Management Science, vol. 30, no. 9, pp. 1078-1092, 1984.

[17] L. Liang, W. D. Cook, and J. Zhu, "DEA models for twostage processes: Game approach and efficiency decomposition," Naval Research Logistics (NRL), vol. 55, no. 7, pp. 643-653, 2008.

[18] L. M. Seiford and J. Zhu, "Profitability and marketability of the top 55 U.S. commercial banks," Management Science, vol. 45, no. 9, pp. 1270-1288, 1999.

[19] C. M. Beckman, M. D. Burton, and C. O’Reilly, "Early teams: The impact of team demography on VC financing and going public," Journal of Business Venturing, vol. 22, no. 2, pp. 147-173, 2007.

[20] M. Bertrand and A. Schoar, "Managing with style: The effect of managers on firm policies," The Quarterly Journal of Economics, vol. 118, no. 4, pp. 1169-1208, 2003.

[21] J. Gimeno, T. B. Folta, A. C. Cooper, and C. Y. Woo, "Survival of the fittest? Entrepreneurial human capital and the persistence of underperforming firms," Administrative Science Quarterly, vol. 42, no. 4, pp. 750-783, 1997.

[22] H. G. Barkema and J. M. Pennings, “Top managment pay: Impact of overt and covert power," Organization Studies, vol. 19, no. 6, pp. 975-1003, 1998.

[23] M. F. Wiersema and K. A. Bantel, "Top management team demography and corporate strategic change," Academy of Management Journal (AMJ), vol. 35, no. 1, pp. 91-121, 1992.

[24] M. Burton, J. B. Sørensen, and C. M. Beckman, “7. Coming from good stock: Career histories and new venture formation," in Social Structure and Organizations Revisited, vol. 19 of Research in the Sociology of Organizations, pp. 229-262, Emerald (MCB UP ), Bingley, 2002.

[25] G. N. Chandler and S. H. Hanks, "An examination of the substitutability of founders human and financial capital in emerging business ventures," Journal of Business Venturing, vol. 13, no. 5, pp. 353-369, 1998.

[26] M. Schefczyk and T. J. Gerpott, "Qualifications and turnover of managers and venture capital-financed firm performance: An empirical study of german venture capital-investments," Journal of Business Venturing, vol. 16, no. 2, pp. 145-163, 2001.

[27] J. Jin, D. Zhou, and P. Zhou, "Measuring environmental performance with stochastic environmental DEA: The case of APEC economies," Economic Modelling, vol. 38, pp. 80-96, 2014.

[28] W. W. Cooper, Z. Huang, and S. X. Li, "Satisficing DEA models under chance constraints," Annals of Operations Research, vol. 66, pp. 279-295, 1996. 


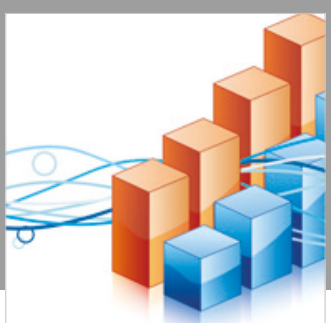

Advances in

Operations Research

\section{-n-m}
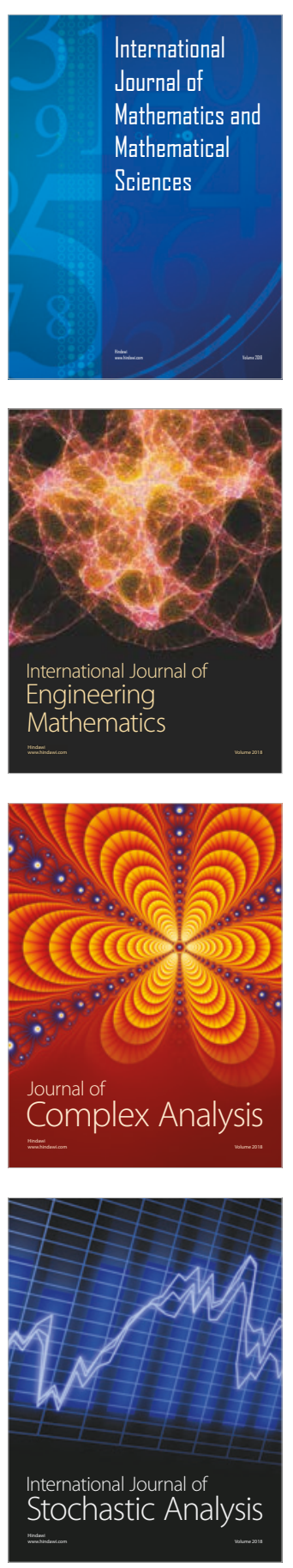
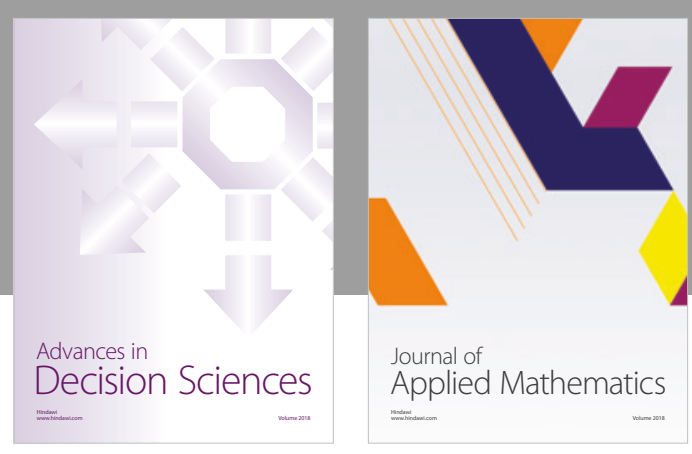

Journal of

Applied Mathematics
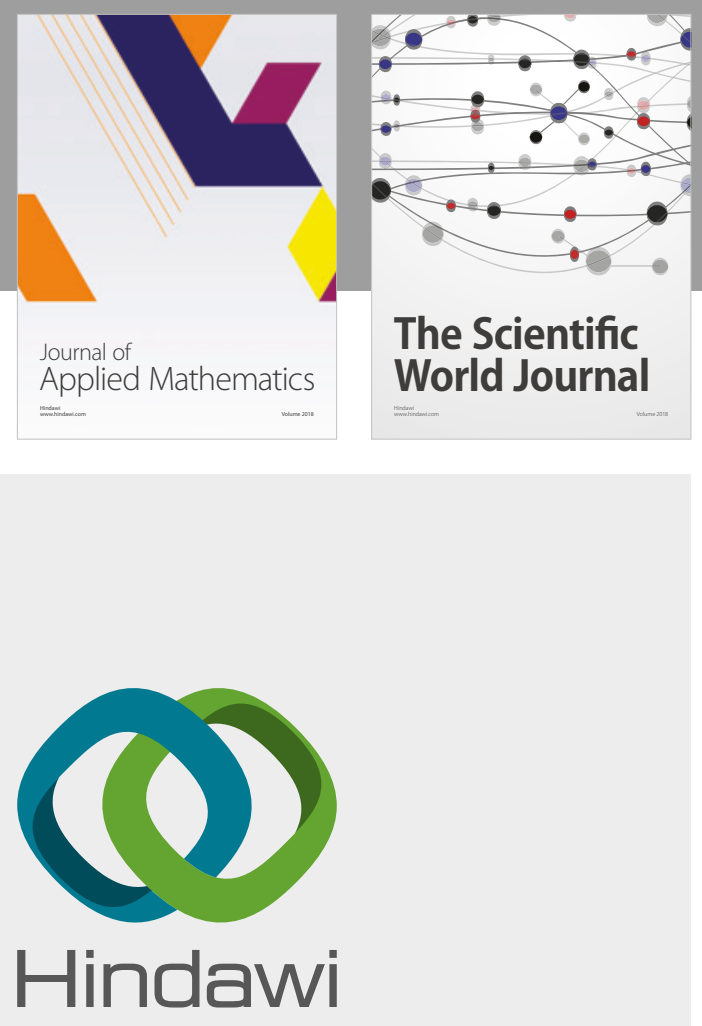

Submit your manuscripts at

www.hindawi.com

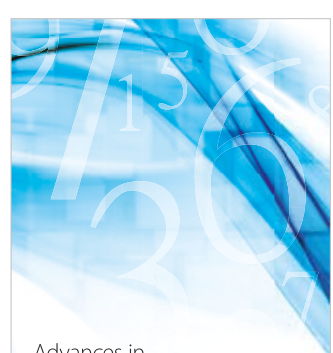

Advances in
Numerical Analysis
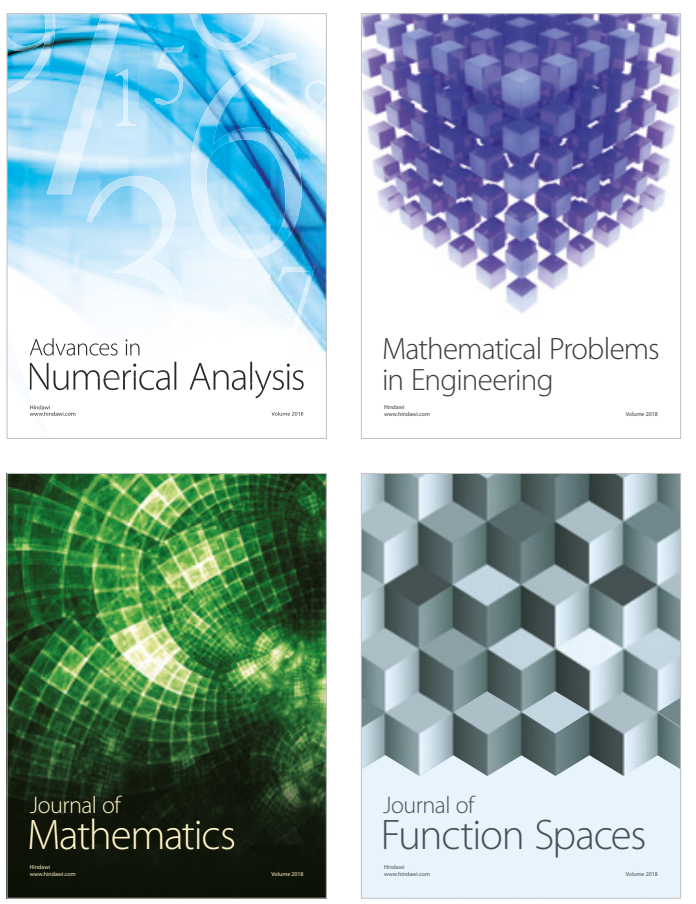

Mathematical Problems in Engineering

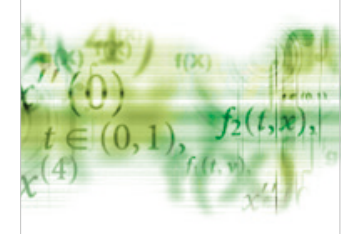

International Journal of

Differential Equations

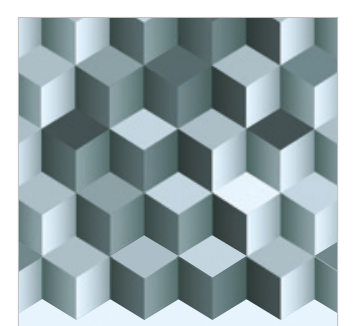

Journal of

Function Spaces
The Scientific

World Journal

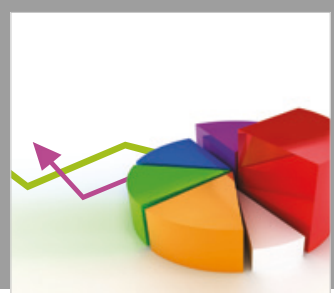

Journal of

Probability and Statistics
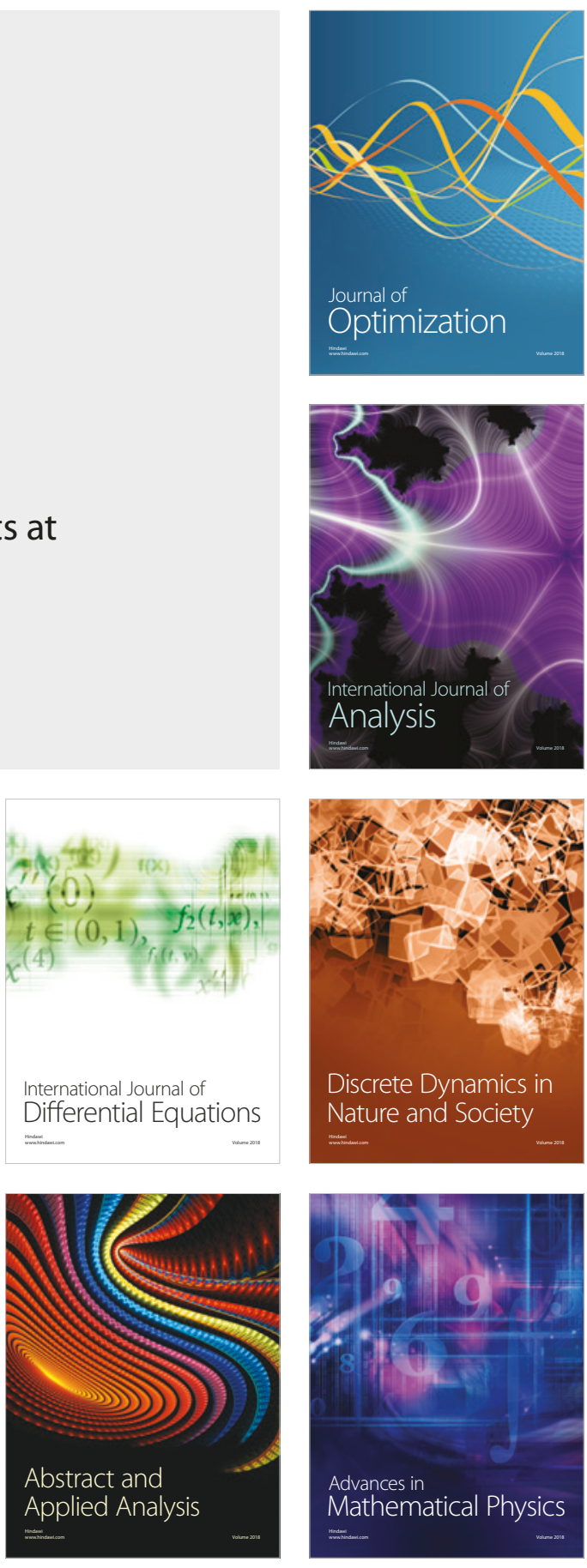